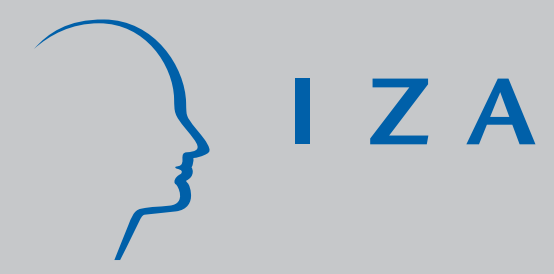

IZA DP No. 3988

Why Praise Inequality? Public Good Provision, Income Distribution and Social Welfare

Indraneel Dasgupta

J anuary 2009 


\title{
Why Praise Inequality? Public Good Provision, Income Distribution and Social Welfare
}

\author{
Indraneel Dasgupta \\ Durham University \\ and IZA
}
Discussion Paper No. 3988
January 2009

\author{
IZA \\ P.O. Box 7240 \\ 53072 Bonn \\ Germany \\ Phone: +49-228-3894-0 \\ Fax: +49-228-3894-180 \\ E-mail: iza@iza.org
}

\begin{abstract}
Any opinions expressed here are those of the author(s) and not those of IZA. Research published in this series may include views on policy, but the institute itself takes no institutional policy positions.

The Institute for the Study of Labor (IZA) in Bonn is a local and virtual international research center and a place of communication between science, politics and business. IZA is an independent nonprofit organization supported by Deutsche Post Foundation. The center is associated with the University of Bonn and offers a stimulating research environment through its international network, workshops and conferences, data service, project support, research visits and doctoral program. IZA engages in (i) original and internationally competitive research in all fields of labor economics, (ii) development of policy concepts, and (iii) dissemination of research results and concepts to the interested public.
\end{abstract}

IZA Discussion Papers often represent preliminary work and are circulated to encourage discussion. Citation of such a paper should account for its provisional character. A revised version may be available directly from the author. 


\begin{abstract}
Why Praise Inequality?

Public Good Provision, Income Distribution and Social Welfare

We consider a two-person Cournot game of voluntary contributions to a public good with identical individual preferences, and examine equilibrium aggregate welfare under a separable, symmetric and concave social welfare function. Assuming the public good is pure, Itaya, de Meza and Myles (Econ. Letters, 57: 289-296; 1997) have shown that maximization of social welfare precludes income equality in this setting. We show that their case breaks down when the public good is impure: there exist individual preferences under which maximization of social welfare necessitates exact income equalization. Even if the public good is pure, any given, positive level of income inequality can be shown to be socially excessive by suitably specifying individual preferences. Thus, sans knowledge of individual preferences, one cannot reject the claim that a marginal redistribution from the rich to the poor will improve social welfare, regardless of how small inequality is in the status quo.
\end{abstract}

JEL Classification: D31, D63, D74, Z13

Keywords: $\quad$ public goods, voluntary provision, income distribution, inequality, social welfare

Corresponding author:

Indraneel Dasgupta

Department of Economics

Durham University

23-26 Old Elvet

Durham DH1 3HY

United Kingdom

E-mail: indraneel.dasgupta@durham.ac.uk 


\section{Introduction}

Rich individuals often voluntarily contribute towards the provision of public goods that are intrinsically important for the well-being of the poor, but have negligible impact on their incomes. Examples of such public goods that routinely acquire rich patrons include places of worship, ethnic festivals, literary and cultural activities, sports clubs, civic/neighborhood amenities (including parks, museums, theatres, community halls, libraries), scientific research, etc. A large literature exists on voluntary provision of public goods with negligible income consequences. This literature typically examines how redistribution of income might influence the equilibrium level of voluntary provision. ${ }^{1}$ A related issue, which has received much less attention, is how voluntary provision affects the normative case for income equalization. Given identical individual preferences, represented by some indirect utility function that is strictly concave in income, maximization of any social welfare function that is symmetric and concave in utilities requires income equalization when all consumption is private. Would voluntary public goods provision by the rich suffice to negate this conclusion?

In a well-known contribution, Itaya et al. (1997) argued that this is indeed the case. Examining the Nash equilibrium of a two-person Cournot game of voluntary contributions to a pure public good, they showed that maximization of social welfare necessarily implies inequality in incomes. ${ }^{2}$ In light of this finding, however, two additional questions immediately suggest themselves.

First, while Itaya et al. (1997) focused on 'pure' public goods, where individual contributions are perfect substitutes, public goods in reality are often better conceptualized as 'impure'. Individuals may derive greater utility from an additional unit of the public good if they themselves provide it, because of the 'warm glow' from the act of giving per se, or due to other private benefits. ${ }^{3}$ Does maximization of social welfare preclude equalization of income when public goods are impure?

Second, even in the empirically restrictive case of pure public goods, does social optimality impose a positive lower bound on inequality, regardless of individual preferences? If not, any arbitrary level of inequality, however small, could be deemed socially excessive under some configuration of individual preferences. Thus, it would not be possible to reject greater equalization independently of individual preferences, even if inequality is arbitrarily small in the status quo. While Itaya et al. (1997) reject exact equalization independently of individual preferences, they remain silent on this issue of 'virtual', or 'almost exact', equalization. Yet, reducing inequality to arbitrarily small levels appears to be of more substantive interest than the limiting construct of exact equalization.

The purpose of this paper is to answer these two questions. As in Itaya et al. (1997), we consider a two-person Cournot game of voluntary contributions to a public good with identical individual

\footnotetext{
1 See Dasgupta and Kanbur (2007, 2005), Cornes and Sandler (2000, 1996), Bergstrom et al. (1986), etc.

2 A related contribution is Cornes and Sandler (2000), who show that redistribution from the poor to the rich can be Pareto-improving in certain contexts. However, unlike Itaya et al. (1997), theirs is not a general defence of inequality. For example, no inequality expanding redistribution is Pareto-improving in a two-person society.

${ }^{3}$ See, for example, Dasgupta and Kanbur (2007), Cornes and Sandler (1994) and Andreoni (1990). The pure public good model implies any income redistribution that leaves the set of contributors unchanged will have no impact on equilibrium consumption bundles: a hypothesis that is typically rejected in empirical investigations.
} 
preferences, and examine equilibrium social welfare under a separable, symmetric and concave social welfare function. We show that, when the public good is impure, there exist individual preferences under which maximization of social welfare entails exact equalization of income. Thus, the case that Itaya et al. (1997) make against equality turns out to be vulnerable in the presence of private benefits from giving. Furthermore, when the public good is pure, any given level of income inequality can be deemed socially excessive by suitably specifying individual preferences. Our results imply that voluntary provision of public goods, by itself, does not necessitate income inequality as a precondition for the maximization of social welfare. Indeed, there exist preference configurations which make equality socially essential under such voluntary provision. Furthermore, sans knowledge of individual preferences, one cannot dismiss the claim that a marginal redistribution from the rich to the poor will improve social welfare, regardless of how small inequality is in the status quo.

Section 2 sets up the model; Section 3 presents our results. Proofs are provided in the Appendix.

\section{The model}

Consider a two person society, ${ }^{4}$ where preferences are given by:

$$
u_{i}=u\left(x_{i}, y_{i}+\eta y_{-i}\right) \text {; }
$$

$x_{i}, y_{i}, y_{-i}$ denoting, respectively, private consumption by individual $i \in\{1,2\}$, the amount of the public good provided by $i$, and the amount provided by the other person; $\eta \in(0,1]$. Thus, individuals have identical preferences. The public good is pure in the special case where $\eta=1$; it is impure in the remaining cases $\eta \in(0,1)$. Both prices are set equal to unity for notational simplicity; total income in society is normalized to one. Let $I_{i}>0$ denote the income of individual $i$; so that $I_{-i}=1-I_{i}$. The two individuals play a standard Cournot game of voluntary contributions to the public good, as in Itaya et al. (1997). Thus, for individual $i \in\{1,2\}$, the optimization problem is:

$$
\begin{aligned}
& \underset{x_{i}, y_{i}}{\operatorname{Max}} u\left(x_{i}, y_{i}+\eta y_{-i}\right) \text { subject to: } \\
& x_{i}+y_{i}=I_{i} \\
& x_{i}, y_{i} \geq 0
\end{aligned}
$$

Denoting the Nash equilibrium utility levels by $u_{1}^{*}, u_{2}^{*}$, aggregate welfare in equilibrium is given by some social welfare function that is symmetric, separable and concave in individual utilities:

$$
W=g\left(u_{1}^{*}\right)+g\left(u_{2}^{*}\right)
$$

where $g^{\prime}>0, g^{\prime \prime}<0$. Since equilibrium utilities depend on the income distribution, so does social welfare. Income redistribution affects social welfare by changing individual utilities in equilibrium.

\footnotetext{
${ }^{4}$ Our analysis can be easily generalized to more than two individuals, without altering our conclusions.
} 


\section{Results}

Does maximization of social welfare necessarily rule out income equality? Lacking knowledge of individual preferences, can one identify some positive magnitude of inequality in the status quo as socially inadequate, in that a marginal rise in inequality will necessarily improve social welfare? We now proceed to answer these questions.

Proposition 1. Suppose the public good is impure $(\eta \in(0,1))$. Then there exist utility functions under which maximization of social welfare necessitates income equalization.

Proof: See the Appendix.

Proposition 1 implies that, given any symmetric, separable and concave social welfare function, voluntary provision of public goods does not, by itself, negate the case for income equalization. Indeed, maximization of social welfare may necessitate exact equality, even though greater inequality elicits greater public good contribution from the rich. There do exist cases where maximization of social welfare precludes exact equality, but, unless the public good is pure, there can be no a priori presumption that this will indeed be so, irrespective of individual preferences.

As Itaya et al. (1997) have shown, such a presumption, independent of individual preferences, is valid when the public good is pure. Nevertheless, even in this case, no amount of wealth inequality, however small, can be presumed to be socially optimal or inadequate, irrespective of individual preferences. This is so because any given magnitude of wealth inequality is socially excessive under particular preference configurations. Thus, without knowledge of individual preferences, one cannot dismiss the claim that a marginal redistribution from the rich to the poor will improve social welfare, regardless of how small inequality is in the status quo. We conclude by formally stating this result.

Proposition 2. Suppose the public good is pure $(\eta=1)$. Then, given any unequal income distribution, there exist utility functions that imply a marginal redistribution from the rich to the poor will improve social welfare.

Proof: See the Appendix.

\section{Appendix}

Proof of Proposition 1. Let preferences be given by: $u_{i}=\lambda \ln x_{i}+\ln \left(y_{i}+\eta y_{-i}\right) ; \eta \in\left(0, \frac{1}{2}\right]$, $\lambda \in \mathfrak{R}_{++}$. Without loss of generality, suppose $I_{1} \equiv \theta<\frac{1}{2}$. Consider any social welfare function: $W=g\left(u_{1}\right)+g\left(u_{2}\right) ; g^{\prime}>0 ; g^{\prime \prime} \leq 0$. Two cases are possible. 
Case 1: $\theta<\frac{\lambda \eta}{1+\lambda+\lambda \eta}<\frac{1}{2}$.

It can be checked that Nash equilibrium consumption is given by: $\left[x_{2}^{*}=(1-\theta)\left(\frac{\lambda}{1+\lambda}\right)\right.$, $\left.y_{2}^{*}=(1-\theta)\left(\frac{1}{1+\lambda}\right), x_{1}^{*}=\theta\right]$. Furthermore, $x_{1}^{*}<x_{2}^{*}$, implying $u_{1}^{*}<u_{2}^{*}$. Thus, $g^{\prime}\left(u_{1}^{*}\right) \geq g^{\prime}\left(u_{2}^{*}\right)$. Now,

$$
\left[u_{1}^{*} \equiv \lambda \ln \theta+\ln \eta+\ln (1-\theta)-\ln (1+\lambda)\right]
$$

and

$\left[u_{2}^{*}=(\lambda+1) \ln (1-\theta)+\lambda \ln \lambda-(1+\lambda) \ln (1+\lambda)\right] . \quad$ Thus, we get: $\quad\left[\frac{\partial u_{1}^{*}}{\partial \theta} \equiv \frac{\lambda(1-\theta)-\theta}{\theta(1-\theta)}\right.$ and $\left.\frac{\partial u_{2}^{*}}{\partial \theta}=-\frac{(\lambda+1) \theta}{(1-\theta) \theta}\right]$, implying $\left[\frac{\partial u_{1}^{*}}{\partial \theta}+\frac{\partial u_{2}^{*}}{\partial \theta} \leq 0\right.$ iff $\left.\theta \geq \frac{\lambda}{2(1+\lambda)}\right]$. However, by assumption, $\theta<\frac{\lambda}{\frac{1}{\eta}+\frac{\lambda}{\eta}+\lambda}<\frac{\lambda}{2(1+\lambda)}$ (since $\eta \leq \frac{1}{2}$ ). Thus, $\frac{\partial u_{1}^{*}}{\partial \theta}+\frac{\partial u_{2}^{*}}{\partial \theta}>0$. Noting that $\frac{\partial u_{2}^{*}}{\partial \theta}<0$, and $g^{\prime}\left(u_{1}^{*}\right) \geq g^{\prime}\left(u_{2}^{*}\right)>0$, we therefore get: $\frac{\partial W}{\partial \theta}>0$.

Case 2: $\frac{\lambda \eta}{1+\lambda+\lambda \eta} \leq \theta<\frac{1}{2}$

In this case, Nash equilibrium consumption is given by: $\left[x_{2}^{*}=\left[(1-\theta)+\eta y_{1}^{*}\left(\frac{\lambda}{1+\lambda}\right)\right.\right.$; $x_{1}^{*}=\left[\theta+\eta y_{2}^{*}\left(\frac{\lambda}{1+\lambda}\right) ; \quad y_{2}^{*}=\frac{(1-\theta)}{1+\lambda}-\frac{\eta y_{1}^{*} \lambda}{1+\lambda} \quad\right.$ and $\left.\quad y_{1}^{*}=\frac{\theta}{1+\lambda}-\frac{\eta y_{2}^{*} \lambda}{1+\lambda}\right] \quad$ Solving, we get: $y_{1}^{*}=\frac{\theta(1+\lambda)-(1-\theta) \eta \lambda}{(1+\lambda)^{2}-\eta^{2} \lambda^{2}}$ and $y_{2}^{*}=\frac{(1-\theta)(1+\lambda)-\theta \eta \lambda}{(1+\lambda)^{2}-\eta^{2} \lambda^{2}}$. Thus, $y_{2}^{*}>y_{1}^{*}$, implying (since $\eta<1$ ); $\left[y_{2}^{*}+\eta y_{1}^{*}\right]>\left[y_{1}^{*}+\eta y_{2}^{*}\right]$. Noting that, for all $i \in\{1,2\},\left[x_{i}^{*}=\lambda\left(y_{i}^{*}+\eta y_{-i}^{*}\right)\right]$, we thus get $x_{2}^{*}>x_{1}^{*}$, and, therefore, $\quad u_{2}^{*}>u_{1}^{*}$, implying $g^{\prime}\left(u_{2}^{*}\right) \leq g^{\prime}\left(u_{1}^{*}\right)$. Notice now that $\left[u_{i}^{*}=(\lambda+1) \ln r_{i}^{*}+\lambda \ln \lambda-(\lambda+1) \ln (1+\lambda)\right]$, where $r_{i}^{*} \equiv I_{i}+\eta y_{-i}^{*}$. Using the solutions for individual contributions, $\quad$ we $\quad$ get: $\quad r_{2}^{*}=\left[(1-\theta)+\frac{\theta \eta(1+\lambda)-(1-\theta) \eta^{2} \lambda}{(1+\lambda)^{2}-\eta^{2} \lambda^{2}}\right]$; $r_{1}^{*}=\left[\theta+\frac{\eta(1-\theta)(1+\lambda)-\theta \eta^{2} \lambda}{(1+\lambda)^{2}-\eta^{2} \lambda^{2}}\right], r_{2}^{*}>r_{1}^{*}$ and $\left[\frac{\partial r_{2}^{*}}{\partial \theta}=-\frac{\partial r_{1}^{*}}{\partial \theta}<0\right]$. As $r_{2}^{*}>r_{1}^{*}$, we have $\frac{\partial u_{2}^{*}}{\partial r_{2}}<\frac{\partial u_{1}^{*}}{\partial r_{1}}$. Recalling $g^{\prime}\left(u_{2}^{*}\right) \leq g^{\prime}\left(u_{1}^{*}\right), \frac{\partial r_{1}^{*}}{\partial \theta}=-\frac{\partial r_{2}^{*}}{\partial \theta}>0$, it follows that $\frac{\partial W}{\partial \theta}>0$. 
Proof of Proposition 2. Let preferences be given by: $u_{i}=\lambda \ln x_{i}+\ln \left(y_{i}+y_{-i}\right) ; \lambda \in \Re_{++}$. Without loss of generality, suppose $I_{1} \equiv \theta<\frac{1}{2}$; and let $\lambda>\frac{2 \theta}{(1-2 \theta)}$. Then, in the Nash equilibrium, $\left[x_{2}^{*}=(1-\theta)\left(\frac{\lambda}{1+\lambda}\right), y^{*}=(1-\theta)\left(\frac{1}{1+\lambda}\right)\right.$, and $\left.x_{1}^{*}=\theta\right]$. We thus get the equilibrium utilities: $\left[u_{1}^{*}=\lambda \ln \theta+\ln (1-\theta)-\ln (1+\lambda)\right.$, and $\left.u_{2}^{*}=(\lambda+1) \ln (1-\theta)+\lambda \ln \lambda-(1+\lambda) \ln (1+\lambda)\right]$. Notice now that $x_{2}^{*} \leq x_{1}^{*}$ iff $\frac{\lambda}{1+\lambda} \leq \frac{\theta}{1-\theta}$; i.e., iff $\lambda \leq \frac{\theta}{(1-2 \theta)}$, which violates our prior assumption $\lambda>\frac{2 \theta}{(1-2 \theta)}$. Hence, $x_{2}^{*}>x_{1}^{*}$, and thus $u_{2}^{*}>u_{1}^{*}$. Consider any social welfare function: $W=g\left(u_{1}\right)+g\left(u_{2}\right) ; \quad g^{\prime}>0 ; g^{\prime \prime} \leq 0$. Since $u_{2}^{*}>u_{1}^{*}, \quad g^{\prime}\left(u_{1}^{*}\right) \geq g^{\prime}\left(u_{2}^{*}\right) . \quad$ Furthermore, given $\lambda>\frac{2 \theta}{(1-2 \theta)},\left[\frac{\partial u_{1}^{*}}{\partial \theta}+\frac{\partial u_{2}^{*}}{\partial \theta}=\frac{\lambda(1-2 \theta)-2 \theta}{\theta(1-\theta)}>0\right]$. Hence, noting $\frac{\partial u_{2}^{*}}{\partial \theta}<0, \frac{\partial W}{\partial \theta}>0$.

\section{References:}

Andreoni, J. (1990): "Impure Altruism and Donations to Public Goods: A Theory of Warm-Glow Giving”, Economic Journal, 100: 464-477.

Bergstrom, T., L. Blume and H. Varian (1986): “On the Private Provision of Public Goods”, Journal of Public Economics, 29: 25-49.

Cornes, R. and T. Sandler (2000): “Pareto-Improving Redistribution and Pure Public Goods”, German Economic Review, 1: 169-186.

Cornes, R. and T. Sandler (1996): The Theory of Externalities, Public Goods and Club Goods, 2nd edn., Cambridge: Cambridge University Press.

Cornes, R. and T. Sandler (1994): “The Comparative Static Properties of the Impure Public Good Model”, Journal of Public Economics, 54: 403-421.

Dasgupta, I. and R. Kanbur (2007): “Community and Class Antagonism”, Journal of Public Economics, 91: 1816-1842.

Dasgupta, I. and R. Kanbur (2005): “Bridging Communal Divides: Separation, Patronage, Integration”, in C. Barrett (ed.), The Social Economics of Poverty: On Identities, Groups, Communities and Networks, London: Routledge.

Itaya, J., D. de Meza and G. Myles (1997): “In Praise of Inequality: Public Good Provision and Income Distribution”, Economics Letters, 57: 289-296. 